\title{
Effects of 20-day litter weight on weaned piglets' fighting behavior after group mixing and on heart rate variability in an isolation test
}

\author{
YaNan Sun ${ }^{1, a}$, XinMing Lian ${ }^{1, a}$, YuKun Bo ${ }^{2}$, YuGuang Guo ${ }^{1}$, and PeiShi Yan ${ }^{1, *}$
}

\begin{abstract}
* Corresponding Author: Peishi Yan Tel: +86-25-84399068, Fax: +86-25-84395314 E-mail: yanps@hotmail.com
\end{abstract}

'College of Animal Science and Technology, Nanjing Agricultural University, Nanjing 210095, China ${ }^{2}$ Animal Husbandry Technology Promotion Institution of Zhangjiakou, Zhangjiakou 075000, China

a These authors contributed equally to this work. Submitted Mar 15, 2016; Revised Apr 21, 2016; Accepted May 10, 2016
Objective: The objective of this study was to investigate the effect of 20-day litter weight on behavior and heart rate variability (HRV) of piglets under stress.

Methods: Forty four original litters were categorized as high litter weight (HW) litters (n $=22)$ and low litter weight $(\mathrm{LW})$ litters $(\mathrm{n}=22)$ by 20 -day litter weight. From each original HW litter, three males and three females were randomly selected after weaning and the 12 piglets from two original litters with similar age of days were regrouped into one new high litter weight (NHW) litter (11 NHW litters in total). The original LW litters were treated with a same program, so that there were 11 new low litter weight (NLW) litters as well. The latencies to first fighting, fighting frequencies and duration within three hours were recorded after regrouping and the lesions on body surface within 48 hours were scored. Besides, HR (heart rate, bpm, beats per minute) and activity count (ACT), time domain indexes and frequency domain indexes of the piglets were measured in an isolation trial to analyze the discrepancy in coping with stress between the original HW and LW litters.

Results: The results exhibited that piglets from the HW litters launched fighting sooner and got statistically higher skin lesion score than those from the LW litters $(\mathrm{p}=0.03$ and 0.02 , respectively). Regarding the HRV detection, compared with the HW litters, the LW litters exhibited a lower mean HR $(\mathrm{p}<0.05)$. In the isolation test, a highly significant higher ACT value was observed between the HW litters, compared to the LW litters $(p<0.01)$. Significant differences were observed in standard deviation of R-R intervals, standard deviation of all normal to normal intervals, and most frequency-domain indicators: very low-frequency, low-frequency, and high frequency between the HW and LW litters as well. The difference in LF:HF was not significant ( $\mathrm{p}=0.779$ ).

Conclusion: This study suggests that compared with litters of low 20-day litter weights, litters with higher 20-day litter weight take more positive strategies to cope with stress and have stronger HRV regulation capacity; HW litters demonstrate better anti-stress and adaptation capacity in the case of regrouping and isolation.

Keywords: Fighting Behavior, Isolation Test, Skin Lesion Score, Heart Rate Variability, Autonomic Nervous System

\section{INTRODUCTION}

Group characteristics are related closely to the subsequent piglets' growth performance and sows' lactation capability in many ways. For example, larger litter size at birth has been proved to be associated with a high incidence of lower body weight gain [1]; litter weight at age of about 20 days can reflect the general lactating capacity of sow before weaning and it has been used as an index of sow's capacity to provide nutrition in evaluating effects of various dietary components on lactating sows [2]. The association between sows' lactation and their offspring's 
aggression has been proved [3]. Fels et al [4] found the presence of litter-associated dominance in social hierarchy when piglets from two litters were mixed after weaning.

Fighting behavior is common in swine husbandry, especially after regrouping and changes in social composition, feed composition or housing [5]. Among these changes, regrouping after weaning may be one of the most serious and commonest causes. For piglets, it is a huge impact to leave the sows, and then to be regrouped for the first time. They have to adapt themselves to the new environment and new feeding regimes, as well as establishing new social hierarchies. Therefore, the piglets will make some changes in their behavior. For example, piglets after regrouping may show fighting or submissive behavior to cope with the stress $[6,7]$. The fighting or submissive behavior depends on various factors, such as body weight, age, group size, and so on [8].

In order to analyze the factors affecting piglets' behaviors under stress, several approaches have been applied in relative researches. Fighting behavior can result in surface lesions. The amount of lesions is closely related to the frequency and duration of fighting, and affected much by the aggressiveness of pigs, for which it is considered as an index of pig's aggressiveness [9]. Besides, it is well known that isolation, similar to regrouping, can lead to repeated excitation, for example vocalization of piglets [10]. This provides an experimental measure to evaluate the adaption capacity of piglets. Furthermore, in order to assess their reaction and stress, the isolation test which can be applied experimentally has been used to determine behavior and heart rate (HR) in animals for decades [11] .

As an index to evaluate excitement of animals, HR can reflect their nervous response to stress in short-term measurements [11]. In recent years, some researchers applied heart rate variability (HRV), the slight disparity between two adjacent cardiac cycles which demonstrated the changes in sensitivity and balance of sympathetic and vagal branches acting on sinoatrial node, in assessing the welfare and stress in animals [12].

For decades, scientists have investigated the measurement indices relevant to HRV, as well as their applications $[13,14]$. High frequency (HF, $\mathrm{ms}^{2}$ ), derived from HRV, is capable of predicting several important human stress markers during night work [15]. Kuwahara et al [16] described the characteristics of HRV in their research to disclose the diurnal variation of autonomic nervous functions of miniature swine, and they found the characteristics of the diurnal variations of swine in autonomic nervous functions were highly similar to those of humans. HRV can reflect the change in autonomic nervous system (ANS) and may be affected by social status of pigs [17]. With the HRV indexes, Marchant-Forde and Marchant-Forde [14] reported the longitudinal dynamics of the cardiac activity on eight occasions at certain fixed time points during pregnancy of primiparous pigs. Therefore, it is obvious that HR and HRV indexes are very useful tools in evaluating animal's responses to stress.

The aim of this research was to disclose effects of the 20-day litter weight on group characteristics of weaned piglets. Fighting behaviors of the piglets in new litters after weaned were observed, including the latency to the first fighting, fighting frequencies and durations, as well as injuries on body surfaces; then an isolation test was conducted to evaluate the effect of 20-day litter weight on cardiac response to stress.

\section{MATERIALS AND METHODS}

\section{Animal care}

The experimental procedure was approved by the Institutional Animal Care and Use Committee at Nanjing Agricultural University.

\section{Subjects}

This research was performed at a pig farm in Qingdao, China. In the research, forty-four litters of piglets (LandracexYorkshire), selected out on the basis of 20-day litter weights from one farrowing house, were included in the study. At age of two days, piglets' teeth were cut, tails were docked and male piglets were castrated manually. From the age of five days, the piglets had free access to creep feed (corn-soybean diet); at the age of 20 days, the piglets were weighted; and at the age of about 26 days, they were weaned and regrouped. In order to eliminate effects of farrowing pens on behaviors, all piglets were raised with their littermates in farrowing pens of a uniform size $(2.15 \mathrm{~m} \times 1.70$ $\mathrm{m} \times 0.50 \mathrm{~m})$, which were equipped with incubators $(0.80 \mathrm{~m} \times$ $0.55 \mathrm{~m} \times 0.50 \mathrm{~m}$ ) and fixed firmly $50 \mathrm{~cm}$ higher over the floor. Then, after weaning, they were moved to nursery pens $(2.20$ $\mathrm{m} \times 1.75 \mathrm{~m} \times 0.70 \mathrm{~m}$ ) which were made from cast iron and 50 $\mathrm{cm}$ above the floor. All pens were swept every afternoon. Light period started from 8:00 AM and lasted for 10 hours. During the experimental period, all piglets had unlimited access to water and food.

The litters before and after regrouping were defined as original litters and new litters, respectively. According to the litter weight at 20-days old, the 44 original litters were categorized into two 22-litter groups, high litter weight (HW) litters with a mean litter weight of $66.64 \pm 8.53 \mathrm{~kg}$ and low litter weight (LW) litters with a mean litter weight of $48.97 \pm 8.97 \mathrm{~kg}$ (mean \pm standard deviation). On the day of weaning, three males and three females in each original HW litter were picked out randomly for the observation of fighting behavior. At 11:00 AM of the experimental date, the total 132 piglets were selected from the original HW litters, arranged in the age order and regrouped into 11 new high litter weight (NHW) litters. Therefore, there were 12 piglets from two original HW litters of closest age of days in one NHW litter. Meanwhile, the same treatment was performed on the original LW litters and 11 new low litter weight litters were obtained.

\section{Fighting trial}

Observation on fighting behavior: In our study, fighting happened 
most frequently during the first several hours after mixing, and after two days later fighting rarely occurred. Therefore, fighting behavior in the first three hours after mixing was observed and skin lesion scores of total 48 hours were recorded. The whole fighting observation process was divided into six time segments (30 minutes per segment). Frequencies and durations of fighting in each time segment were recorded. In addition, latency to the first fighting, which meant the period from start of regrouping to the first fight for each piglet was recorded as well. The term "fighting" herein was defined as 'mutual pushing and ramming the opponent with the head or shoulders in rapid succession with or without biting more than one second [8]. When the fighting participants separated from each other for five seconds or longer, the fighting was considered to be terminated [18]. Between separate fights there must be an interval of at least 30 seconds. Duration of an individual fight was recorded from the time when an attempt to push or ram appeared to the time when the fighting terminated. No data was recorded for piglets that were not involved in fighting. During the observation period, the environmental temperature in nursery house was controlled at $26^{\circ} \mathrm{C}$ to $28^{\circ} \mathrm{C}$.

Skin lesion score: All lesions and scratches on each pig's body were recorded separately following the criteria of Melotti et al [19] during the first 48 hours after regrouping by the same observer to evaluate and compare fighting intensities of the piglets. In order to disclose the effect of time period on skin lesion score, the observation period was also divided into three segments, 0 to $3 \mathrm{~h}, 3$ to $24 \mathrm{~h}$, and 24 to $48 \mathrm{~h}$, and new skin lesion scores in the three time segments were recorded respectively.

\section{HRV in isolation test}

Isolation test: At the age of 33 days and 34 days, namely 7th and 8 th days after weaning respectively, each nursery pen was divided into two parts using a metal board. Four female weanlings were randomly selected from each new litter and were separated in turn from other pen-mates and from water and food, using a frame steel bar. Before the formal experiment, Actiheart (a compact, chest-worn non-invasive device recording HR, HRV, and physical activity, produced by Cambridge Neurotechnology Ltd., Papworth Everard, UK) was fixed to each piglet in an appropriate position described as below, in order to get the piglet adapted to the device. Then, the piglet was kept isolated from other pen-mates for 30 minutes. In the isolation test, the temperature in the nursery house was controlled at $24^{\circ} \mathrm{C}$ to $26^{\circ} \mathrm{C}$ with heating lamps.

Actiheart is a device used to measure HRV indexes, capable of measuring acceleration, HR, HRV, and ECG (electrocardiogram) amplitude with a certain time resolution. Available epoch settings included $15 \mathrm{~s}, 30 \mathrm{~s}$ and $1 \mathrm{~min}$, and the epoch in data acquisition of HR and activity count (ACT) was set at the $15 \mathrm{~s}$ in this study. Then, a short term procedure was chosen. Body length and weight of each piglet, measured just before HRV detection, were input into the software, and start time of the Actiheart was set. The hair on the body areas covered by the Actiheart was shaved and the areas were cleaned up thoroughly using $4 \%$ saline solution before placement of the electrode pads. The main sensor was placed in the midline just below the xiphisternum. Two standard electrocardiograph electrode pads (Shanghai Junkang Medical Equipment Co., Ltd, Shanghai, China) were fixed respectively horizontally onto the left and middle, respectively, of first pair of teats, approximately 13 to $15 \mathrm{~cm}$ away from each other. Then the sensors and the electrode pads were surrounded and protected with an elastic belt, in order to hold them stable. The Actiheart started at the set time when isolation began. After the measurement finished, the data was downloaded to the laptop computer from the Actiheart for subsequent analysis. The same observer operated on all the piglets.

Heart rate variables: In the study, HRV analysis included the detections of the HR and ACT, time-domain analysis and frequency-domain analysis. HR referred to the frequency of the heartbeat in one minute; ACT was an index to account the amount of piglets' activity (mainly meant duration and intensity of activity) in one minute. Time domain analysis comprised the standard deviation of R-R intervals (SD, ms), the standard deviation of all normal to normal intervals (SDNN, ms), the standard deviation of the average normal to normal intervals calculated over five minutes (SDANN, ms) and the root mean square of successive differences (RMSSD, ms)[13]. Frequency domain analysis comprised the very low-frequency below 0.04 $\mathrm{Hz}\left(\mathrm{VLF}, \mathrm{ms}^{2}\right.$ ), the low-frequency from 0.04 to $0.15 \mathrm{~Hz}\left(\mathrm{LF}, \mathrm{ms}^{2}\right.$ ), the HF from 0.15 to $0.4 \mathrm{~Hz}$ and the LF/HF [13].

All indexes above were detected and displayed using the Achiheart in real time.

\section{Statistical analysis}

Kolmogorov-Smirnov test was used to test for normality of all data. Those not conforming to normal distribution were processed through logarithmic transformation for the following analysis. Then, the data of HW and LW litters were processed by SPSS 20.0 and analyzed using general linear mixed model, with litter weight and time segments as the fixed effect. Results are given as mean \pm standard error of the mean, except for the litter weight values of 20-day. Before analysis on fighting behavior, piglets without fighting were excluded from the analysis. Records with poor quality, possibly due to loose connection between electrode pads and skin of some piglets, were removed from the related analysis either.

Furthermore, the differences in fighting behavior and HRV indexes among the time segments in each group and the difference between two groups of different litter weight were analyzed using non-parameters test. Differences were considered significant at $\mathrm{p}<0.05$. 

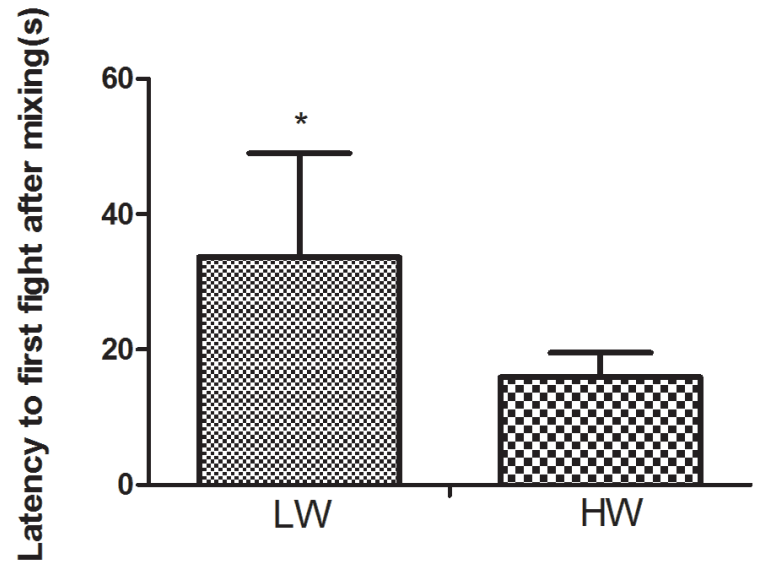

Figure 1. Comparison in latencies to the first fight after regrouping between the low litter weight (LW) and high litter weight (HW) litters. The asterisk $\left({ }^{*}\right)$ shows the significant difference with $p<0.05$; group means and standard errors are given in all figures.

\section{RESULTS}

\section{Fighting behavior}

Effects of different litter weights on fighting behaviors in piglets: Latencies to the first fighting after regrouping in the LW litters were significantly longer than that in the HW litters $(33.68 \pm 15.37$ $\mathrm{s}$ vs $15.93 \pm 3.60 \mathrm{~s}, \mathrm{p}=0.03$; Figure 1$)$. The piglets performed excitedly in the first hour in both groups after regrouped. Then, they trended to calm down gradually, except in the segment of 2.5 to $3.0 \mathrm{~h}$ (Table 1). Significantly more frequent and longer fighting behavior was observed in the last time segment than that in the previous one segment in the LW litters. No significant difference in the fighting frequency or duration was observed between the LW litters and the HW litters.

Skin lesion score: Before the regrouping process above, no visible lesion on the body surface of any piglets was observed. Litter weight had significant effect on the mean skin lesion score $(p=0.02$, Table 2). Lesions appeared mostly in the first day after mixing ( 0 to $3 \mathrm{~h}$ and 3 to $24 \mathrm{~h}$ ) and only a few new lesions appeared in the second day ( 24 to $48 \mathrm{~h}$ ).
Table 2. Effects of 20-day litter weight and time on skin lesion score after mixing

\begin{tabular}{lccc}
\hline \multirow{2}{*}{ Time segment } & \multicolumn{3}{c}{ Skin lesion score after mixing } \\
\cline { 2 - 4 } & LW & HW & p-value \\
\hline $3 \mathrm{~h}$ & $0.65 \pm 0.08^{\mathrm{A}}$ & $0.70 \pm 0.09^{\mathrm{B}}$ & 0.81 \\
$24 \mathrm{~h}$ & $0.88 \pm 0.12^{\mathrm{A}}$ & $1.16 \pm 0.12^{\mathrm{A}}$ & 0.04 \\
$48 \mathrm{~h}$ & $0.23 \pm 0.05^{\mathrm{B}}$ & $0.36 \pm 0.05^{\mathrm{B}}$ & 0.05 \\
Mean & $0.59 \pm 0.05$ & $0.74 \pm 0.05$ & 0.02 \\
\hline
\end{tabular}

LW, low litter weight; HW, high litter weight.

Means in the same column with different superscripts differ, $p<0.05$.

\section{HRV in the isolation tests}

Due to the bad connection between the Actiheart sensor and the skin surface of ten piglets in the HW litters and four piglets in the LW litters, records of 74 piglets were available for HRV analysis, with 34 piglets from the LW group and 40 piglets from the HW group, respectively.

$A C T$ and HR: Mean HR in LW litters was very significantly less than that in HW litters $(\mathrm{p}<0.05)$. As well, a marked difference was observed in ACT $(p=0.01)$ (Table 3$)$. HR value in HW litters was larger, and the ACT value of piglets in LW litters was significantly higher (Figure 2).

Effects on time domain analysis: As shown in Table 3 and 4, the time domain analysis for the HW litters got higher results than for the LW litters, but the differences in SDANN and RMSSD were not significant. A highly significant difference was observed in SD value between the HW litters and the LW litters ( $31.15 \pm 0.96$ vs $27.11 \pm 0.09, \mathrm{p}<0.01)$. For both of the two groups, $S D$ value obtained in the first five minutes was significantly bigger than that in second one, and then the value changed little till end of the isolation test. There was no significant fluctuation observed in RMSSD values during the test period.

Result of frequency domain analysis: Outcomes of the frequency domain analysis were listed in Table 3 and 5. By comparison, the mean LF value of LW litters was very significantly lower than that of the HW litters $(p<0.01)$. Regarding the mean HF value, it was exactly the opposite $(p=0.01)$. A very significant difference was also observed in VLF between HW group and LW group $(\mathrm{p}<0.01)$. For both of the HW and LW litters, VLF and LF exhibited little variation during the whole isolation period.

Table 1. Differences in fighting behaviors between LW group and HW group within first 3 hours after regrouped

\begin{tabular}{|c|c|c|c|c|c|c|c|c|c|c|c|}
\hline \multirow{2}{*}{$\begin{array}{l}\text { Time } \\
\text { segment }\end{array}$} & \multicolumn{3}{|c|}{ Total duration (s/0.5 h) } & \multicolumn{3}{|c|}{ Frequency (fights/0.5 h) } & \multicolumn{5}{|c|}{ Mean duration (s/fight) } \\
\hline & $\mathrm{LW}$ & HW & p-value & LW & HW & $p$-value & $\mathrm{LW}$ & $\mathbf{n}$ & HW & $\mathbf{n}$ & $p$-value \\
\hline $0-0.5 \mathrm{~h}$ & $292.11 \pm 128.73^{A}$ & $359.50 \pm 145.80^{A}$ & 0.71 & $5.40 \pm 2.70^{A}$ & $5.36 \pm 2.01^{\mathrm{A}}$ & 0.56 & $73.33 \pm 13.90^{A}$ & 28 & $65.04 \pm 13.17^{A B}$ & 56 & 0.34 \\
\hline $0.5-1 h$ & $281.34 \pm 89.91^{\mathrm{AB}}$ & $253.2 \pm 145.32^{A B}$ & 0.20 & $4.50 \pm 0.91^{A B}$ & $2.36 \pm 0.85^{A B}$ & 0.10 & $62.81 \pm 9.56^{\mathrm{A}}$ & 42 & $92.82 \pm 21.48^{A}$ & 30 & 0.96 \\
\hline $1-1.5 h$ & $169.07 \pm 73.22^{A B}$ & $102.92 \pm 56.34^{\mathrm{AB}}$ & 0.28 & $3.20 \pm 1.17^{A B}$ & $1.55 \pm 0.69^{A B}$ & 0.22 & $60.58 \pm 11.29^{A}$ & 26 & $47.17 \pm 10.22^{A B}$ & 24 & 0.25 \\
\hline $1.5-2 \mathrm{~h}$ & $96.03 \pm 77.50^{A B}$ & $88.40 \pm 37.47^{A B}$ & 0.43 & $2.20 \pm 1.55^{\mathrm{AB}}$ & $1.82 \pm 0.57^{\mathrm{AB}}$ & 0.47 & $41.75 \pm 9.58^{A B}$ & 23 & $40.52 \pm 7.80^{B}$ & 24 & 0.89 \\
\hline $2-2.5 h$ & $25.09 \pm 17.25^{B}$ & $51.87 \pm 38.43^{B}$ & 0.65 & $0.50 \pm 0.34^{B}$ & $0.73 \pm 0.45^{B}$ & 0.65 & $20.91 \pm 8.99^{B}$ & 12 & $38.04 \pm 13.15^{B}$ & 15 & 0.43 \\
\hline $2.5-3 \mathrm{~h}$ & $178.22 \pm 62.70^{A B}$ & $149.76 \pm 63.68^{\mathrm{AB}}$ & 0.71 & $3.00 \pm 1.03^{\mathrm{A}}$ & $3.00 \pm 1.33^{A B}$ & 0.76 & $56.84 \pm 7.34^{A}$ & 27 & $44.52 \pm 8.92^{B}$ & 37 & 0.04 \\
\hline Mean & $173.64 \pm 34.28$ & $167.60 \pm 39.00$ & 0.51 & $3.13 \pm 0.61$ & $2.47 \pm 0.48$ & 0.38 & $57.04 \pm 4.54$ & 26.3 & $57.79 \pm 5.98$ & 31.0 & 0.18 \\
\hline
\end{tabular}

LW, low litter weight; HW, high litter weight.

Group means and standard errors are given in all tables; means in the same column with different superscripts differ, $p<0.05$; the untagged results in a same column have no statistically significant difference; $n$ represents the count of fightings in each time segment. 
Table 3. General comparison in HR, ACT, and HRV variables between LW and HW groups during isolation test

\begin{tabular}{lccc}
\hline Variables & LW & HW & p-value \\
\hline $\mathrm{n}$ & 34 & 40 & - \\
$\mathrm{HR}(\mathrm{bpm})$ & $151.90 \pm 1.60$ & $157.30 \pm 1.65$ & 0.03 \\
$\mathrm{ACT}($ counts/min) & $264.00 \pm 16.45$ & $409.40 \pm 19.88$ & 0.00 \\
SD & $27.11 \pm 0.09$ & $31.15 \pm 0.96$ & 0.00 \\
SDNN (ms) & $47.19 \pm 2.82$ & $53.49 \pm 2.33$ & 0.04 \\
SDANN (ms) & $35.26 \pm 2.70$ & $38.79 \pm 2.55$ & 0.23 \\
RMSSD (ms) & $18.74 \pm 0.93$ & $20.58 \pm 0.97$ & 0.12 \\
VLF (ms $\left.{ }^{2}\right)$ & $119.60 \pm 10.80$ & $157.70 \pm 13.88$ & 0.00 \\
LF (ms & $132.50 \pm 10.11$ & $168.10 \pm 10.75$ & 0.00 \\
HF $\left(\mathrm{ms}^{2}\right)$ & $144.10 \pm 20.20$ & $132.4 \pm 12.89$ & 0.01 \\
\hline HR & &
\end{tabular}

$H R$, heart rate; $A C T$, activity count; HRV, heart rate variability; LW, low litter weight; HW, high litter weight; SD, standard deviation of R-R intervals; SDNN, standard deviation of all normal to normal intervals; SDANN, standard deviation of the average normal to normal intervals; RMSSD, root mean square of successive differences; VLF, very low-frequency; LF, low-frequency; $H F$, high frequency.

Significant fluctuations happened on the HW group only, in HF value and the ratio of LF to HF among the time segments. The difference in the ratio of LF to HF between the LW and HW litters was not statistically significant $(\mathrm{p}=0.779)$.

For all indicators in this paper, there was no significant interaction of the effects of litter weight and time.

\section{DISCUSSION}

This study disclosed the effects of 20-day litter weight on fighting behavior and cardiac activities of piglets. One major finding in this study was that HW piglets were more positive in coping with stress and had quicker adaptation to the new environment in case of regrouping and isolation, in comparison with LW piglets.

\section{Fighting behavior and skin lesion scores}

This study showed the difference in responding to regrouping between HW litters and LW litters. It was observed, similar to the research of Bolhuis et al [20], that the piglets in HW litters started fighting significantly earlier than the LW litters. Besides, the remarkably higher mean skin lesion score also implied HW litters were more positive in fighting behavior than LW litters after regrouping. Normally, piglets that gained more weight before weaning were more aggressive while those that gained less weight are more submissive [3]. In the present study, the marked differences in latency to the first fight and skin lesion score probably involved the difference in coping strategies to stress between HW litters and LW litters. Therefore, as a positive indicator of piglets adapting to environment changes, a shorter mean latency to the first fight in the HW piglets reflected the difference between positive coping strategy and negative coping strategy [19]. The variation in fighting duration and frequencies further supported this conclusion. When it came close to end of the trial (the time segment of 2.5 to $3 \mathrm{~h}$ ), both HW and LW litters exhibited similar trends in mean values of fighting frequencies and duration, but the change in LW litters were more obvious, as indicated by the significant differences in frequency and mean duration between the last two time segments (Table $3)$. Influenced by circadian rhythms, most piglets were in a relatively peaceful state and crouching down in the time segment of 2 to 2.5 h, i.e. 1:00 PM to 1:30 PM [21]. Then, they gradually reactivated in the next time segment of 2.5 to $3.0 \mathrm{~h}$, i.e. 1:30 $\mathrm{PM}$ to 2:00 PM. In the sixth $30 \mathrm{~min}$, the significance in change

Table 4. Comparison in time-domain indexes between LW and HW groups during isolation test

\begin{tabular}{|c|c|c|c|c|c|c|}
\hline \multirow{2}{*}{ Time segment } & \multicolumn{3}{|c|}{$\mathrm{SD}(\mathrm{ms})$} & \multicolumn{3}{|c|}{ RMSSD (ms) } \\
\hline & $\mathrm{LW}$ & HW & $p$-value & $\mathrm{LW}$ & HW & p-value \\
\hline $0-5 \mathrm{~min}$ & $41.66 \pm 2.27^{\mathrm{A}}$ & $40.24 \pm 3.12^{A}$ & 0.44 & $19.12 \pm 1.90$ & $20.93 \pm 2.63$ & 0.90 \\
\hline $5-10 \mathrm{~min}$ & $22.79 \pm 1.86^{B}$ & $27.24 \pm 2.30^{B}$ & 0.16 & $16.68 \pm 2.08$ & $18.01 \pm 2.55$ & 0.69 \\
\hline $10-15 \mathrm{~min}$ & $23.48 \pm 1.71^{B}$ & $28.79 \pm 2.18^{A B}$ & 0.06 & $18.07 \pm 2.22$ & $21.37 \pm 2.44$ & 0.37 \\
\hline $15-20 \mathrm{~min}$ & $24.99 \pm 2.08^{B}$ & $29.17 \pm 1.67^{A B}$ & 0.09 & $17.38 \pm 1.85$ & $19.84 \pm 1.89$ & 0.32 \\
\hline $20-25 \mathrm{~min}$ & $24.07 \pm 1.87^{B}$ & $30.67 \pm 1.97^{A B}$ & 0.01 & $20.64 \pm 2.33$ & $22.85 \pm 2.55$ & 0.51 \\
\hline $25-30 \mathrm{~min}$ & $25.63 \pm 2.71^{B}$ & $30.85 \pm 2.12^{\mathrm{AB}}$ & 0.04 & $20.94 \pm 3.26$ & $20.50 \pm 2.26$ & 0.52 \\
\hline
\end{tabular}

LW, low litter weight; HW, high litter weight; SD, standard deviation of R-R intervals; RMSSD, root mean square of successive differences.

Means in the same column with different superscripts differ, $p<0.05$; the untagged results in a same column have no statistically significant difference.

Table 5. Comparison in frequency-domain indexes between LW and HW groups during isolation test

\begin{tabular}{|c|c|c|c|c|c|c|c|c|c|c|c|c|}
\hline \multirow{2}{*}{$\begin{array}{l}\text { Time } \\
\text { segment }\end{array}$} & \multicolumn{3}{|c|}{$\operatorname{VLF}\left(\mathrm{ms}^{2}\right)$} & \multicolumn{3}{|c|}{$\operatorname{LF}\left(m s^{2}\right)$} & \multicolumn{3}{|c|}{$\mathrm{HF}\left(\mathrm{ms}^{2}\right)$} & \multicolumn{3}{|c|}{ LF:HF } \\
\hline & LW & HW & p-value & LW & $\mathrm{HW}$ & $p$-value & LW & HW & $p$-value & LW & HW & $p$-value \\
\hline $0-5 \mathrm{~min}$ & $146.20 \pm 34.04$ & $139.33 \pm 27.09$ & 0.91 & $138.08 \pm 33.47$ & $133.22 \pm 25.26$ & 0.91 & $81.17 \pm 23.94$ & $86.00 \pm 28.35^{A}$ & 0.90 & $2.82 \pm 0.32$ & $2.72 \pm 0.26 \mathrm{~A}$ & 0.81 \\
\hline 5-10 min & $114.22 \pm 26.83$ & $155.19 \pm 33.61$ & 0.16 & $125.70 \pm 25.11$ & $168.92 \pm 27.98$ & 0.22 & $120.97 \pm 42.80$ & $94.06 \pm 22.38^{A}$ & 0.18 & $3.40 \pm 0.43$ & $3.17 \pm 0.38 \mathrm{~A}$ & 0.76 \\
\hline $10-15 \mathrm{~min}$ & $123.00 \pm 31.19$ & $164.95 \pm 24.71$ & 0.09 & $107.90 \pm 14.87$ & $195.92 \pm 27.86$ & 0.04 & $129.19 \pm 43.52$ & $203.49 \pm 41.42^{\mathrm{B}}$ & 0.12 & $2.88 \pm 0.42$ & $2.67 \pm 0.42 \mathrm{AB}$ & 0.48 \\
\hline $15-20 \mathrm{~min}$ & $119.42 \pm 18.86$ & $126.86 \pm 18.6$ & 0.53 & $122.42 \pm 19.53$ & $157.47 \pm 20.92$ & 0.16 & $110.03 \pm 27.29$ & $112.03 \pm 15.62^{A B}$ & 0.09 & $2.83 \pm 0.40$ & $1.86 \pm 0.23 B$ & 0.11 \\
\hline $20-25 \mathrm{~min}$ & $112.83 \pm 22.24$ & $177.23 \pm 45.58$ & 0.15 & $164.09 \pm 28.85$ & $150.46 \pm 21.90$ & 0.69 & $189.03 \pm 52.62$ & $132.69 \pm 27.16^{\mathrm{AB}}$ & 0.66 & $2.02 \pm 0.23$ & $2.24 \pm 0.36 \mathrm{~B}$ & 0.92 \\
\hline $25-30 \mathrm{~min}$ & $99.44 \pm 22.00$ & $184.74 \pm 48.42$ & 0.01 & $139.28 \pm 23.10$ & $203.56 \pm 32.55$ & 0.08 & $247.88 \pm 89.12$ & $166.21 \pm 43.19^{A B}$ & 0.36 & $2.20 \pm 0.31$ & $2.67 \pm 0.37 A B$ & 0.54 \\
\hline
\end{tabular}

LW, low litter weight; HW, high litter weight; VLF, very low-frequency; LF, low-frequency; HF, high frequency.

Means in the same column with different superscripts differ, $p<0.05$; the untagged results in a same column have no statistically significant difference. 
of fighting frequencies and duration in LW litters suggested that piglets in LW litters were still sensitive to the new environment in this time segment, compared with those in HW litters. This possibly also reflected that the LW litters were slower in adapting to a new environment than the HW litters.

$\mathrm{Li}$ and Wang [21] thought that it was competition for resources that led to fighting after regrouping. However, further studies indicated that fighting was the process to establish a new dominance status and was the main reason for most of the fighting behaviors within the first several hours after regrouping [20]. Our results supported the later opinion, and the sharply decreased amount of lesion score in the second day ( 24 to $48 \mathrm{~h}$ ) suggested the dominant cause of fighting probably was the generation of a new social hierarchy, rather than simple competition for resources. Thus, the insignificant difference in fighting duration and frequency between LW and HW litters might involve the familiarity with the original social hierarchy. The familiarity or unfamiliarity among piglets could seriously affect the aggressiveness of piglets during the generation of new dominance status, and it was reported that only $5 \%$ of total fighting time occurred between familiar pigs [21]. It was found that a piglet growing with littermates in familiar rearing environment seldom started fighting with other litter-mates spontaneously [22]. In addition, the original social hierarchy of piglets influenced the
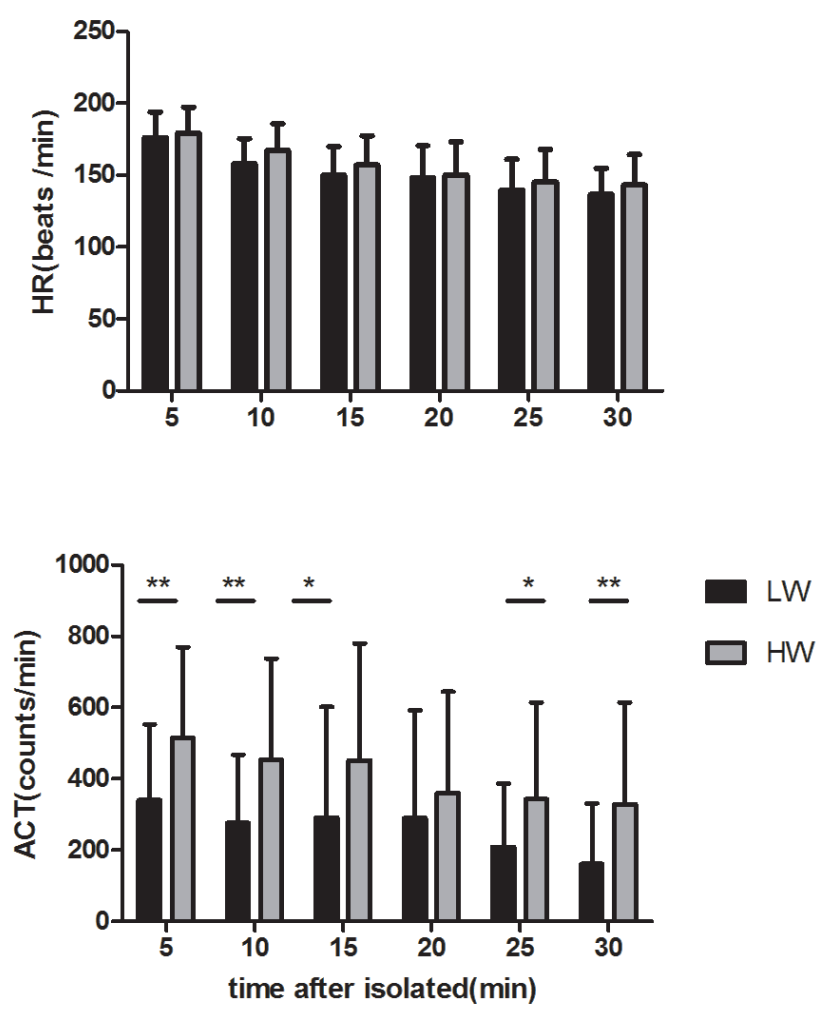

Figure 2. Comparison in heart rate (HR) and activity count (ACT) between the low litter weight (LW) and high litter weight (HW) litters litters in piglets (calculated every $5 \mathrm{~min})$. The asterisk (*) means a significant difference with $p<0.05$; the asterisk $\left(^{* *}\right)$ means very significant difference with $p<0.01$. skin scores as well [23]. In this study, six piglets in each new litter originated from a same original litter and the other six came from another one, in accordance with practical regrouping scheme of the pig farm. Thus, the familiarity and the original social rank decreased the incidence of fighting, meanwhile probably caused the insignificant differences in fighting frequency and duration between the HW litters and LW litters.

\section{Effects of litter weight on HR, ACT, and HRV}

Concerning the detection of HR and ACT, the results provided further evidence to the existence of difference in coping strategies and adaptation capacities associated to the litter weight. In addition, we found piglets in LW litters preferred to rest or mainly move in corners, while the HW piglets performed more aggressively and preferred to move along the barrier, even tried to bite it. The HW piglets exhibited obvious exploratory behaviors and significantly bigger ACT values, in comparison to the LW piglets, which was additional evidence for a positive coping strategy of HW litters. The previous studies we found concerning HR or HRV exhibited variable HR levels of swine (mainly involving miniature piglets and new born piglets), ranging from 80.0 to $163.1 \mathrm{bpm}[16,17]$, but there was no information concerning HR of weaned piglets under stress. Our results suggested that the HR of piglets under stress covered a wide range from 96 to $224 \mathrm{bpm}$ and the mean value was $154.2 \pm 1.15 \mathrm{bpm}$ (not listed in tables). HR was reported to be mainly regulated synergistically by sympathetic nervous system and vagal system [24]. As far as the cardiac nerve activity is concerned, a significantly larger HR value may be caused by reduced vagal activity, or by increased sympathetic activity, or, in most cases, by interaction between them [13]. However, various factors can affect HR. Therefore, the difference in HR between LW and HW litters was not enough to confirm whether the higher HR in the HW litters indicated less vagal activities or more sympathetic nerve tension than that in the LW litters. According to the predication formula for basic HR on basis of body weight, LW piglets would have a theoretical basic HR of $169.6 \mathrm{bpm}$, higher than our result of $151.9 \mathrm{bpm}$, while the LW piglets would have a basic HR of $157.4 \mathrm{bpm}$, exactly the result in the present study (157.2 bpm) [25]. In addition, the significant difference in the physical activities, reflected by ACT, could also affect values of HR [26]. This may be another reason for the discrepancy in HR. However, the HR results, as a net outcome of ANS, can reflect a marked discrepancy in net interactions of vagal (reducing HR) and sympathetic (increasing HR) regulations between the two groups [24].

With the HRV indexes, we investigated the deep-seated factors of various coping strategies and the roles of sympathetic and vagal systems in coping with continuous stress. The ANS regulation intensity is a well-proved indicator for adaptation of animals $[14,17,27]$. The time domain analysis supported our conclusion about the fighting behavior. SD and SDNN reflected the general regulation condition of HRV and served as an indica- 
tor of ANS intension $[23,24]$. Our results suggested that the HW litters exhibited stronger general HRV regulation capacity and better anti-stress capacity in comparison with their LW counterparts. Besides, the changes in SD of both groups indicated that under conditions of isolation, intension state of ANS would be released within $10 \mathrm{~min}$ after the piglets were isolated. Another important index, RMSSD reflected the regulation of vagal system [13]. In the previous measurement on RMSSD by de Jong et al [17], the mean baseline of RMSSD ranged within 14.5 to 33.0 $\mathrm{ms}$, and our results were in a wider range of 3.51 to $76.29 \mathrm{~ms}$. Besides, this study exhibited relatively mild changes of RMSSD with time in both of the two groups, which might be related to the span of one time segment. It was within the first $80 \mathrm{~s}$ after stimulation that the RMSSD of piglets $(\mathrm{n}=24)$ could respond fiercely in case of stimulation [28]. In order to evaluate the general change of ANS, each time segment in this study was set at 5 minutes, much longer than the $80 \mathrm{~s}$ mentioned above. This was possibly a reason for the apparently mild RMSSD variation with time in our results. Besides, the stable RMSSD value might relate to the attempt of continuous vagal tone to decrease HR of piglets. Isolation was a continuous stress for the piglets and anxiety and stress lasted over the whole test period, and HR value maintained at a relatively high level throughout the experiment. Thus, vagal system became intense and the excitation was stable at a high level during the whole experimental period.

Similarly, the frequency domain analysis also exhibited the stronger regulation capacity of ANS in the HW litters. The LF values could reflect the complex regulation of ANS, which was similar to the effect of SD [24]. Medical research about HRV analysis of deaths from heart disease suggested that patients with higher LF values exhibited greater survival rates from heart diseases, which implied better self-regulation of ANS and adaptation capacities in the people under challenging situations [27]. The higher LF values in the HW litters suggested better ANS regulation capacities, which was consistent with the conclusion in fighting observation. The LF values changed smoothly during the whole experimental period as well, which happened possibly because the excitation of sympathetic nerve was maintaining at a relatively high level but not released within the 30 min after start of the isolation. HF was a fast variation component in HRV, with a similar effect of RMSSD, and reflected the excitation of vagus [24]. Some scholars think HRV of isolated pigs is mainly controlled by vagus [29]. The increasing tendency of HF in both of the HW and LW litters might be related to a continuously enhanced state of vagus system in the isolation test. However, they had different fluctuation waves. In the HW litters, the maximal mean value appeared at the time segment of 10 to $15 \mathrm{~min}$, and then the mean HF value decreased sharply, followed by mild increase. A significant variation with time occurred in the HW group, possibly reflecting relatively stronger regulation of the vagal system. In the LW litters, mean HF value exhibited a continuous increasing tendency in general. In comparison, it is obvious that the mean HF value in the LW litters increased more sharply, reflecting stronger regulation of vagus, than that in the HW litters, opposite to the general variation tendencies in mean LF values. Koolhaas et al [30] thought that the excitement of sympathetic nervous system was more active in a positive coping strategy, whereas the vagal system was more active in a negative coping strategy, which might be supported by our results above.

The LF/HF ratio reflected the stress level and increased value of LF/HF would be observed while the body suffered from stress as indicated by Hainsworth [24]. In the trial, litter weight did not have significant effect on this ratio, which proved that the piglets in the two groups were stressed equivalently. The mean ratio of LF to HF in the study was much higher than the normal value in both of the two groups (close to 1.0, [16]). It was proved in a study on humans that some stress (total sleep deprivation for $36 \mathrm{~h}$ with continuous stimulation) could lead to a linear increase in the excitation of sympathetic nerve and a decrease in that of vagus [31]. The decrease in the LF/HF ratio, though not significant, could reflect a shift towards dominance of vagal system as well [13].

\section{CONCLUSION}

The findings in this study indicate that HW litters are more positive in fighting and adapting to a new environment in the case of regrouping and isolation, compared with LW counterparts. In the case of isolation, piglets of different litter weights are stressed equivalently. HW litters demonstrate stronger general ANS regulation than LW litters. In both of the two groups, the general sympathetic and vagal tones increase continuously, sympathetic nerve dominates in the HRV regulation, and the dominance lasts throughout the process under stress but gets weaker gradually. However, in case of stress, HW litters and LW litters have different ANS regulation modes. Understanding the effects of 20-day litter weight has the potential to contribute much to prediction of general anti-stress performance at a very early time. Offspring of sows with better lactating capacity possibly have positive coping strategies and are better in adaptation to new environment, which can help predicting anti-stress capacity and adaptability of piglets before weaning.

\section{CONFLICT OF INTEREST}

We certify that there is no conflict of interest with any financial organization regarding the material discussed in the manuscript.

\section{ACKNOWLEDGMENTS}

This research was supported by the Special Fund for Agri-scientific Research in the Public Interest from the Ministry of Agriculture 
(Project No.: 201003011).

\section{REFERENCES}

1.Mesa H, Safranski TJ, Johnson RK, Lamberson WR. Correlated response in placental efficiency in swine selected for an index of components of lifter size. J Anim Sci 2003;81:74-9.

2.Wang J, Yang $\mathrm{M}, \mathrm{Xu} \mathrm{S}$, et al. Comparative effects of sodium butyrate and flavors on feed intake of lactating sows and growth performance of piglets. Anim Sci J 2014;85:683-9.

3.Algers B, Jensen P, Steinwall L. Behaviour and weight changes at weaning and regrouping of pigs in relation to teat quality. Appl Anim Behav Sci 1990;26:143-55.

4.Fels M, Hoy S, Hartung J. Influence of origin litter on social rank, agonistic behaviour and growth performance of piglets after weaning. Appl Anim Behav Sci 2012;139:225-32.

5.Colson V, Martin E, Orgeur P, Prunier A. Influence of housing and social changes on growth, behaviour and cortisol in piglets at weaning. Physiol Behav 2012;107:59-64.

6.Melotti L, Oostindjer M, Bolhuis JE, Held S, Mendl M. Coping personality type and environmental enrichment affect aggression at weaning in pigs. Appl Anim Behav Sci 2011;133:144-53.

7.Rhim S-J, Son S-H, Hwang H-S, Lee J-K, Hong J-K. Effects of Mixing on the Aggressive Behavior of Commercially Housed Pigs. AsianAustralas J Anim Sci 2015;28:1038-43.

8.Samarakone TS, Gonyou HW. Domestic pigs alter their social strategy in response to social group size. Appl Anim Behav Sci 2009; 121:8-15

9.Turner SP, Roehe R, D'Eath RB, et al. Genetic validation of postmixing skin injuries in pigs as an indicator of aggressiveness and the relationship with injuries under more stable social conditions. J Anim Sci 2009;87:3076-82.

10. Fraser D. Vocalizations of isolated piglets. I. Sources of variation and relationships among measures. Applied Animal Ethology 1975; 1:387-94.

11. Pollard JC, Littlejohn RP. Consistency in avoidance of humans by individual red deer. Appl Anim Behav Sci 1995;45:301-8.

12. Zupan M, Janczak AM, Framstad T, Zanella AJ. The effect of biting tails and having tails bitten in pigs. Physiol Behav 2012;106:63844.

13. von Borell E, Langbein J, Després G, et al. Heart rate variability as a measure of autonomic regulation of cardiac activity for assessing stress and welfare in farm animals - A review. Physiol Behav 2007; 92:293-316

14. Marchant-Forde RM, Marchant-Forde JN. Pregnancy-related changes in behavior and cardiac activity in primiparous pigs. Physiol Behav 2004;82:815-25.

15. Lee H-H, Chen B-Y, Lo S-H, Chen P-C, Guo Y-L. 0248 Predicting physician's duty stress by parasympathetic nervous function (also to be considered for mini-symposium: Early detection and management of workers under stress). Occup. Environ. Med. Suppl 2014; 71:A93.1-A.
16. Kuwahara M, Suzuki A, Tsutsumi H, Tanigawa M, Tsubone H, Sugano S. Power spectral analysis of heart rate variability for assessment of diurnal variation of autonomic nervous activity in miniature swine. Lab Anim Sci 1999;49:202-8.

17. de Jong IC, Sgoifo A, Lambooij E, Korte SM, Blokhuis HJ, Koolhaas JM. Effects of social stress on heart rate and heart rate variability in growing pigs. Can J Anim Sci 80:273-80.

18. Stookey JM, Gonyou HW. Recognition in swine: recognition through familiarity or genetic relatedness? Appl Anim Behav Sci 1998;55: 291-305.

19. Melotti L, Oostindjer M, Bolhuis JE, Held S, Mendl M. Coping personality type and environmental enrichment affect aggression at weaning in pigs. Appl Anim Behav Sci 2011;133:144-53.

20. Bolhuis JE, Schouten WGP, Schrama JW, Wiegant VM. Individual coping characteristics, aggressiveness and fighting strategies in pigs. Anim Behav 2005;69:1085-91.

21. Li Y, Wang L. Effects of previous housing system on agonistic behaviors of growing pigs at mixing. Appl Anim Behav Sci 2011;132: 20-6.

22. Forkman BaMH. The maintenance of stable dominance hierarchies and the pattern of aggression: support for the suppression hypothesis. Ethology 2005;110:737-44.

23. Séguin MJ, Barney D, Widowski TM. Assessment of a group-housing system for gestating sows:Effects of space allowance and pen size on the incidence ofsuperficial skin lesions, changes in body condition, and farrowing performance. J Swine Health Prod 2006;14: 89-96.

24. Hainsworth R. The control and physiological importance of heart rate. In: Heart Rate Variability 1995.

25. Stahl WR. Scaling of respiratory variables in mammals. J Appl Physiol 1967;22:453-60.

26. Physick-Sheard PW, Marlin DJ, Thornhill R, Schroter RC. Frequency domain analysis of heart rate variability in horses at rest and during exercise. Equine Vet J 2000;32:253-62.

27. Ponikowski P, Anker SD, Chua TP, et al. Depressed heart rate variability as an independent predictor of death in chronic congestive heart failure secondary to ischemic or idiopathic dilated cardiomyopathy. Am J Cardiol 1997;79:1645-50.

28. Dupjan S, Tuchscherer A, Langbein J, Schon PC, Manteuffel G, Puppe B. Behavioural and cardiac responses towards conspecific distress calls in domestic pigs (Sus scrofa). Physiol Behav 2011; 103:445-52

29. Porges SW. The Polyvagal Theory: phylogenetic contributions to social behavior. Physiol Behav 2003;79:503-13.

30. Koolhaas JM, Korte SM, De Boer SF, et al. Coping styles in animals: current status in behavior and stress-physiology. Neurosci Biobehav Rev 1999;23:925-35.

31. Zhong X, Hilton HJ, Gates GJ, et al. Increased sympathetic and decreased parasympathetic cardiovascular modulation in normal humans with acute sleep deprivation. J Appl Physiol (1985) 2005; 98:2024-32. 